\title{
STUDY OF DENTITION IN LIZARDS FROM GRAN CANARIA ISLAND (CANARY ISLANDS) AND ITS ECOLOGICAL AND EVOLUTIONARY SIGNIFICANCE
}

\author{
J. A. Mateo ${ }^{1}$, L. F. López-Jurado² \\ 1 Estación Biológica Doñana (CSIC), Pabellón del Perú, Avenida de María Luisa s/n, 41013 Seville, Spain. \\ 2 Departamento de Biología, Universidad de Las Palmas de Gran Canaria, Apartado Postal 550, 35080 Las Palmas, Canary Islands, \\ Spain.
}

\begin{abstract}
The dentition of Gallotia stehlini from one extant and two subfossil populations dated as 4000 and 2000 years before present was studied. Body measurements were similar in the two subfossil populations, but much greater than the largest sizes observed today in G. stehlini. The morphology of the dental cusps in this G. stehlini differs greatly from that of other Lacertidae, including other congeneric Canarian species; this has been connected with a vegetarian diet. A decrease in heterodonty with size of the animal is also seen which contrasts strongly with the models observed in the Mediterranean lacertid lizards.
\end{abstract}

